Jurnal Abdidas Volume 2 Nomor 5 Tahun 2021 Halaman 1224 - 1227

JURNAL ABDIDAS

http://abdidas.org/index.php/abdidas

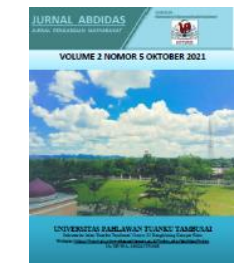

\title{
Hidup Berdamai dengan Hipertensi
}

\author{
Sintha Fransiske Simanungkalit ${ }^{1}$, Duma Lumbantobing ${ }^{2}$, Sang Ayu Made Adyani ${ }^{3}$ \\ Universitas Pembangunan Nasional Veteran Jakarta, Indonesia ${ }^{1,2,3}$

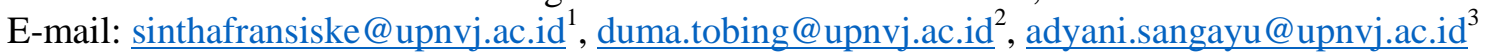

\begin{abstract}
Abstrak
Tekanan darah tinggi atau yang dikenal dengan hipertensi adalah kondisi ketika kekuatan darah yang mendorong dinding arteri saat jantung memompa darah tinggi daripada keadaan normal. Menurut Seventh Report of Joint National Comitte (JNC-7), seseorang dikatakan mengalami hipertensi apabila tekanan darah sistolik $\geq 140 \mathrm{mmHg}$ dan atau tekanan darah sistolik $\geq 90 \mathrm{mmHg}$ tanpa mengonsumsi obat anti hipertensi. Lansia adalah mereka yang telah berusia 65 tahun ke atas. Kegiatan ini berlangsung di POSBINDU Dahlia Senja, Limo, Depok. Kegiatan ini berupa penyuluhan dan pemberian kuesioner untuk melihat apakah ada perubahan pengetahuan sebelum dan sesudah penyuluhan. Berdasarkan hasil analisis data didapatkan ada perbedaan sebelum dan sesudah penyuluhan. Penyuluhan cukup efektif mengubah pengetahuan kader. Kegiatan pengabdian masyarakat ini bertujuan untuk memberikan informasi dalam kegiatan edukasi gizi kepada para kader, sehingga diharapkan dapat menambah pengetahuan yang nantinya akan merubah sikap dan perilaku lansia terkait pencegahan dan penanggulangan hipertensi.
\end{abstract}

Kata kunci: hipertensi, pengetahuan, kader

\begin{abstract}
High blood pressure, also known as hypertension, is a condition when the force of blood pushing against the artery walls when the heart pumps blood is higher than normal. According to the Seventh Report of the Joint National Committee (JNC-7), a person is said to have hypertension if the systolic blood pressure is $\geq 140$ $\mathrm{mmHg}$ and or systolic blood pressure $\geq 90 \mathrm{mmHg}$ without taking anti-hypertensive drugs. Elderly are those aged 65 years and over. This activity took place at POSBINDU Dahlia Senja, Limo, Depok. This activity is in the form of counseling and giving questionnaires to see if there is a change in knowledge before and after the counseling. Based on the results of data analysis, it was found that there were differences before and after counseling. Counseling is quite effective in changing the knowledge of cadres. This community service activity aims to provide information in nutrition education activities to cadres, so that it is hoped that it can increase knowledge which will later change the attitudes and behavior of the elderly related to hypertension prevention and control.
\end{abstract}

Keywords: hypertension, knowledge, cadres

Copyright (c) 2021 Sintha Fransiske Simanungkalit, Duma Lumbantobing, Sang Ayu Made Adyani

$\triangle$ Corresponding author

Address : Universitas Pembangunan Nasional Veteran Jakarta

ISSN 2721-9224 (Media Cetak)

Email : sinthafransiske@upnvj.ac.id

ISSN 2721- 9216 (Media Online)

DOI : https://doi.org/10.31004/abdidas.v2i5.438 
1225 Hidup Berdamai dengan Hipertensi - Sintha Fransiske Simanungkalit, Duma Lumbantobing, Sang Ayu Made Adyani

DOI: https://doi.org/10.31004/abdidas.v2i5.438

\section{PENDAHULUAN}

Menurut World Health Organitation

(WHO), lansia adalah seseorang yang telah memasuki usia 60 tahun keatas. Lansia merupakan kelompok umur pada manusia yang telah memasuki tahapan akhir dari fase kehidupannya. Kelompok yang dikategorikan lansia ini akan terjadi suatu proses yang disebut Aging Process atau proses penuaan.

Proses penuaan adalah siklus kehidupan yang ditandai dengan tahapan-tahapan menurunnya berbagai fungsi organ tubuh, yang ditandai dengan semakin rentannya tubuh terhadap berbagai serangan penyakit yang dapat menyebabkan kematian misalnya pada sistem kardiovaskuler dan pembuluh darah, pernafasan, pencernaan, endokrin dan lain sebagainya. Hal tersebut disebabkan seiring meningkatnya usia sehingga terjadi perubahan dalam struktur dan fungsi sel, jaringan, serta sistem organ. Perubahan tersebut pada umumnya mengaruh pada kemunduran kesehatan fisik dan psikis yang pada akhirnya akan berpengaruh pada ekonomi dan sosial lansia. Sehingga secara umum akan berpengaruh pada activity of daily living (Fatmah, 2010). Kota Depok menempati urutan ke-13 dari seluruh kota di Jawa Barat dengan penderita hipertensi. Dengan prevalensi sebesar $9.02 \%$ dan berdasarkan pengukuran tekanan darah pada usia $\geq 15$ tahun pada tahun 2019, wilayah Pasir Putih memiliki 5.932 kasus hipertensi dengan $8.4 \%$ pasien mendapat pelayanan kesehatan (Dinas Kesehatan Kota Depok 2020).

Besarnya masalah hipertensi di kota Depok menjadi acuan tim pengabdi melakukan kegiatan pengabdian masyarakat ini di wilayah Limo, Depok.

\section{METODE}

Kegiatan pengabdian masyarakat ini berlangsung di Limo, Depok yang dilakukan bulan Juni. Adapun sasaran kegiatan ini adalah para kader Posyandu dan Posbindu. Pada kegiatan pengabdian masyrakat ini, sebelum kader diberikan penyuluhan para kader akan diberikan pre test untuk mengukur pengetahuan kader. Setelah kader mengisi pre test dilanjutkan sesi edukasi gizi lewat video.

Media video pembelajaran adalah seperangkat komponen atau media yang mampu menampilkan gambar sekaligus suara dalam waktu bersamaan (Sukiman, 2012). Media video yang digunakan dalam proses belajar mengajar memiliki banyak manfaat dan keuntungan, diantaranya adalah video merupakan pengganti alam sekitar dan dapat menunjukkan objek yang secara normal tidak dapat dilihat oleh audiens secara langsung. Video ini berisikan Informasi tentang pencegahan dan penanggulangan Hipertensi yang bisa disaksikan secara langsung oleh para lansia menggunakan bantuan projector dan speaker. Target yang ingin dicapai dalam kegiatan ini adalah perubahan pengetahuan kader yang diukur berdasarkan post test. Data para kader akan dianalisis dengan perangkat computer dengan uji Wilcoxon. 
1226 Hidup Berdamai dengan Hipertensi - Sintha Fransiske Simanungkalit, Duma Lumbantobing, Sang Ayu Made Adyani

DOI: https://doi.org/10.31004/abdidas.v2i5.438

\section{HASIL DAN PEMBAHASAN}

Penyuluhan gizi adalah proses belajar untuk mengembangkan pengertian dan sikap yang positif terhadap gizi agar yang bersangkutan dapat memiliki dan membentuk kebiasaan makan yang baik dalam kehidupan sehari - hari (Depkes, 1991). Tujuan dari penyuluhan gizi adalah sebagai berikut :

1) Meningkatan kesadaran masyarakat melalui peningkatan pengetahuan gizi dan makanan yang menyehatkan

2) Menyebarkan konsep baru tentang informasi gizi pada masyarakat

3) Membantu individu, keluarga, dan masyarakat secara keseluruhan berperilaku positif sehubungan dengan pangan dan gizi

4) Mengubah perilaku dan kebiasaan konsumsi makananyang sesuai dengan tingkat kebutuhan gizi, sehingga pada akhirnya tercapai status gizi yang baik.

Program penyuluhan gizi hipertensi ini merupakan salah satu bentuk pendidikan gizi yang melibatkan lansia dan atau pendamping lansia yang bermanfaat bagi mereka dalam hal mencegah dan menanggulangi hipertensi melalui penambahan informasi pengetahuan, sikap dan perubahan perilaku yang dikarenakan kurangnya pengetahuan.

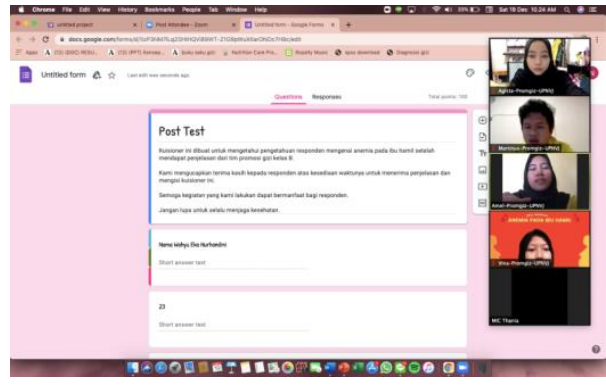

Gambar 1. Penyuluhan dan Penyebaran Kuesioner via Daring

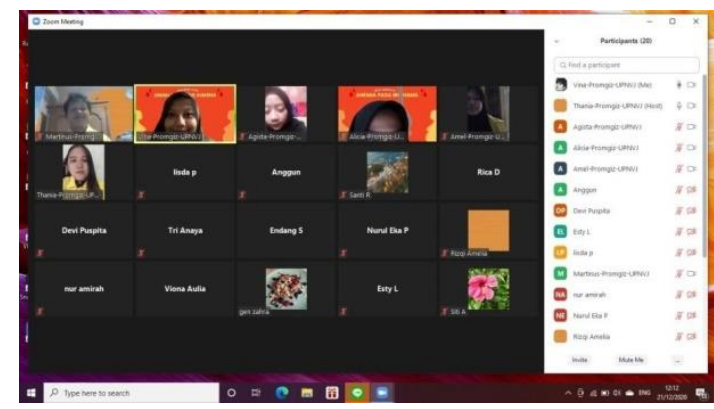

Gambar 2. Sesi Tanya Jawab dan Sesi Penutpan via Daring

Berikut hasil analisis pengetahuan para kader:

Tabel 1. Nilai Skor Pengetahuan Kader

\begin{tabular}{llllll}
\hline & N & Mean & $\begin{array}{l}\text { Std. } \\
\text { Deviation }\end{array}$ & Min & Max \\
\hline Pretest & 10 & 3.50 & 1.179 & 1 & 5 \\
\hline Posttest & 10 & 4.40 & 0.843 & 3 & 5 \\
\hline
\end{tabular}

Untuk mengetahui apakah terdapat pengetahuan sebelum dan sesudah responden diberi penyuluhan dengan media (video) yang tim pengabdian gunakan, jumlah jawaban benar dari masing-masing pre-test dan post-test kemudian dianalisis secara statistik dengan uji Wilcoxon dengan signifikansi 0,05 .

Berdasarkan tabel 1 dapat disimpulkan bahwa secara deskriptif terdapat perbedaan pengetahuan sebelum dan sesudah diberikan penyuluhan gizi, yang dapat dilihat dari adanya 
1227 Hidup Berdamai dengan Hipertensi - Sintha Fransiske Simanungkalit, Duma Lumbantobing, Sang Ayu Made Adyani

DOI: https://doi.org/10.31004/abdidas.v2i5.438

kenaikan nilai rata-rata (mean) jumlah jawaban benar dari 3.50 pada pre-test menjadi 4.40 pada post-test. Pre-test menunjukkan pengetahuan sebelum penyuluhan dan post-test menunjukkan pengetahuan setelah diadakan penyuluhan gizi.

Tabel 2 Hasil Uji Wilcoxon

\begin{tabular}{lc}
\hline & Bnrpost - Bnrpre \\
\hline $\mathbf{Z}$ & -2.460 \\
Asym.Sig (2-tailed) & .014 \\
\hline
\end{tabular}

Berdasarkan tabel di atas (Tabel 2), terlihat nilai uji Wilcoxon $(Z)=-2.460$ dan Nila asym.sig $(2$-tailed $)=0.014$. Nilai asym.sig $(2$-tailed $)=0.014$ $<$ alpha (0.05), berarti terdapat perbedaan yang signifikan antara jumlah jawaban benar sebelum dan sesudah penyuluhan menggunakan media video dan kalender yang kami gunakan. Hasil perubahan pengetahuan yang signifikan melalui penggunaan media penyuluhan video terhadap lansia sejalan dengan penelitian yang dilakukan oleh Supit et al (2018), yang mana hasil penelitiannya juga menunjukkan hasil yang signifikan terhadap pengetahuan lansia dengan penggunaan media video. Selain itu, penelitian yang dilakukan oleh Priwanci (2010) juga menunjukkan adanya pengaruh pendidikan kesehatan tentang hipertensi dengan peningkatan pengetahuan responden.

\section{SIMPULAN}

Berdasarkan hasil analisis data pengetahuan kader didapatkan bahwa penyuluhan dengan metode video dapat merubah pengetahuan sebelum dan sesudah kader. Saran dari pengabdian masyarakat ini agar para kader rutin diberikan penyuluhan gizi sehingga diharapkan para kader dapat berbagi pengetahuan terkait hipertensi kepada masyarakat di tempat mereka tinggal.

\section{UCAPAN TERIMA KASIH}

Tim dosen UPN Veteran Jakarta berterima kasih atas LPPM UPN Veteran Jakarta, FIKES UPN Veteran Jakarta, Kelurahan Limo dan para kader yang turut berperan aktif dalam kegiatan ini.

\section{DAFTAR PUSTAKA}

Dinas Kesehatan Kota Depok. 2020. "Profil Kesehatan Kota Depok 2019." Profil Dinas Kesehatan Kota Depok: 1-116. Http://Dinkes.Depok.Go.Id/.

Kilic M, Et Al. 2016. The Effect Of Knowledge About Hypertension On The Control Of High Blood Pressure. International Journal of The Cardiovascular Academy. 2(1):27-31.

Priwanci, Indar.2010. Pengaruh Pendidikan Kesehtana Tentang Hipertensi Stadium I Terhadap Pengetahuan Dan Sikap Keluarga Dalam Menjalankan 5 Tgas Keluarga Di Wilayah Kerja Puskesmas.Mojo. SKRIPSI. Universitas Airlangga, Surabaya.

Sukiman. 2012. Pengembangan Media Pembelajaran. Yogyakarta : Pedagogia

Supit J , Dkk. 2018. Efektifitas Pemberian Edukasi Dengan Metode Video Dan FGD Terhadap Tingkat Pengetahuan Pasien DMT2 DI Klinik Diabetes Kimia Farma Husada Manado. E-Journal Keperawatan. 6(1):1-6. 